\section{OPEN ACCESS}

Approved by:

Frontiers Editorial Office

Frontiers Media SA, Switzerland

*Correspondence:

Patricio E. Ramírez-Correa patricio.ramirez@ucn.cl

Specialty section:

This article was submitted to Human-Media Interaction,

a section of the journal

Frontiers in Psychology

Received: 27 August 2021

Accepted: 31 August 2021

Published: 22 September 2021

Citation:

Ramírez-Correa PE

Rondán-Cataluña FJ,

Arenas-Gaitán J, Grandón EE

Alfaro-Pérez $J L$ and

Ramírez-Santana M (2021)

Corrigendum: Segmentation of Older

Adults in the Acceptance of Social

Networking Sites Using Machine

Learning. Front. Psychol. 12:765840.

doi: 10.3389/fpsyg.2021.765840

\title{
Corrigendum: Segmentation of Older Adults in the Acceptance of Social Networking Sites Using Machine Learning
}

\section{Patricio E. Ramírez-Correa ${ }^{1 *}$, F. Javier Rondán-Cataluña ${ }^{2}$, Jorge Arenas-Gaitán ${ }^{2}$, Elizabeth E. Grandón ${ }^{3}$, Jorge L. Alfaro-Pérez ${ }^{1}$ and Muriel Ramírez-Santana ${ }^{4}$}

${ }^{1}$ School of Engineering, Universidad Católica del Norte, Coquimbo, Chile, ${ }^{2}$ Department of Business Administration and Marketing, University of Seville, Seville, Spain, ${ }^{3}$ Department of Information Systems, University of Bío-Bío, Concepción, Chile, ${ }^{4}$ Department of Public Health, Universidad Católica del Norte, Coquimbo, Chile

Keywords: acceptance, elderly, social network sites, heterogeneity, machine learning

\section{A Corrigendum on}

Segmentation of Older Adults in the Acceptance of Social Networking Sites Using Machine Learning

by Ramírez-Correa, P. E., Rondán-Cataluña, F. J., Arenas-Gaitán, J., Grandón, E. E., Alfaro-Pérez, J. L., and Ramírez-Santana, M. (2021). Front. Psychol. 12:705715. doi:10.3389/fpsyg.2021.705715

In the published article, there was an error in affiliation 1 and 4. Instead of "Catholic University of the North," it should be "Universidad Católica del Norte."

The authors apologize for this error and state that this does not change the scientific conclusions of the article in any way. The original article has been updated.

Publisher's Note: All claims expressed in this article are solely those of the authors and do not necessarily represent those of their affiliated organizations, or those of the publisher, the editors and the reviewers. Any product that may be evaluated in this article, or claim that may be made by its manufacturer, is not guaranteed or endorsed by the publisher.

Copyright (c) 2021 Ramírez-Correa, Rondán-Cataluña, Arenas-Gaitán, Grandón, Alfaro-Pérez and Ramírez-Santana. This is an open-access article distributed under the terms of the Creative Commons Attribution License (CC BY). The use, distribution or reproduction in other forums is permitted, provided the original author(s) and the copyright owner(s) are credited and that the original publication in this journal is cited, in accordance with accepted academic practice. No use, distribution or reproduction is permitted which does not comply with these terms. 